\title{
Analysis and Study on Bending Vibration Frequency of New Corrugated Steel Web Composite Box Girder
}

\author{
Xiaomeng Zang $(\mathbb{D}$, Genhui Wang, and Zichen Zhang \\ School of Civil Engineering, Lanzhou Jiaotong University, Lanzhou, Gansu 730070, China \\ Correspondence should be addressed to Xiaomeng Zang; zangxm@lzjtu.edu.cn
}

Received 23 September 2021; Revised 15 October 2021; Accepted 19 October 2021; Published 16 November 2021

Academic Editor: Sang-Bing Tsai

Copyright (C) 2021 Xiaomeng Zang et al. This is an open access article distributed under the Creative Commons Attribution License, which permits unrestricted use, distribution, and reproduction in any medium, provided the original work is properly cited.

\begin{abstract}
In order to accurately analyze the bending vibration frequency of the new composite box girder, the effects of web folding effect, shear lag, and shear deformation are comprehensively considered in this paper, and the elastic control differential equation and natural boundary conditions of the composite box girder are established by using the Hamilton principle. A one-span composite box girder with corrugated steel webs is used as a numerical example. The effects of height span ratio, width span ratio, web thickness, cantilever plate length, and fold effect on the vertical vibration frequency of the new composite box girder are analyzed. The results show that the analytical solution is in good agreement with the finite element solution. When considering the shear lag and fold effect, the vibration frequency of composite box girder decreases. With the increase in order, the influence of shear lag and fold effect on its frequency becomes stronger. The changes of height span ratio and web thickness of composite box girder have a great influence on its folding effect, while the changes of width span ratio and cantilever plate length have little influence on it. The conclusion can provide a reference for the design of medium section new composite bridge in practical engineering.
\end{abstract}

\section{Introduction}

Corrugated steel web bridge is a kind of composite structure bridge appeared at the end of the twentieth century [1-5]. Compared with the flat steel web bridge, the corrugated steel web has superior shear performance, higher out of plane stiffness, and strong landscape beauty. At the same time, the wrinkle effect of the corrugated steel web also improves the prestress application efficiency, effectively solves the structural diseases caused by temperature stress, shrinkage, creep, and other factors [6-10], and performs well in earthquake resistance $[11,12]$. However, under the action of positive bending moment, the concrete floor of this traditional corrugated steel web composite box girder is tensioned, which requires more prestressed tendons, and the construction is more complex and takes a long time [3, 13-17]. In recent years, in order to improve the construction progress, further reduce the self weight of the structure, and enhance the seismic performance of the bridge structure, bridge workers have proposed the design of a new composite box girder bridge by replacing the traditional corrugated steel web composite box girder bottom plate (RC plate) with flat steel plate. The self weight of this kind of structure is reduced by more than $50 \%$ compared with the traditional corrugated steel web composite box girder and makes full use of the characteristics of compression of concrete roof, tension of steel bottom plate, and high shear yield strength of corrugated steel web. At present, many bridges in Gansu Province of China have adopted this new type of composite structure, for example, Taohe bridge, Anlin highway, Dongxiang County, Linxia city, and Gansu Province. However, there is no clear calculation method for the natural vibration frequency of this type of bridge in the relevant specifications, which shows that the bridge workers still have a lack of understanding of the mechanical properties of this new corrugated steel web composite box girder bridge. Since the bending vibration frequency of the bridge is the basis for calculating its impact coefficient and analyzing the seismic performance of the bridge $[18,19]$, it is very important to accurately solve the bending vibration frequency of the new 
composite box girder, which has strong theoretical and engineering practical significance.

Based on the energy variational principle and comprehensively considering the effects of shear lag and shear deformation, the dynamic elastic control differential equation and natural boundary conditions of the new composite box girder are derived in this paper. Based on this, the natural frequency equation of simply supported composite box girder is obtained. Combined with the finite element analysis results and the measured values of the model, the accuracy of this method is verified. Furthermore, the effects of shear lag effect, height span ratio, width span ratio, corrugated web thickness, and cantilever plate length on the vertical bending vibration frequency of the new composite box girder are analyzed. According to the current external environmental conditions and the characteristics of the bridge, the method used in this paper enriches and develops the analysis theory of this kind of structure and has certain guiding significance for the design of new corrugated steel web composite beam structure.

\section{Elastic Governing Differential Equation}

2.1. Basic Assumptions of Calculation. Combined with the stress characteristics of the section of the new composite box girder, the following basic assumptions are given: (1) in the elastic working range of composite box girder, there is no relative slip between web and roof; (2) the upper and lower wing plates of the composite box girder always meet the "quasi plane section assumption"; and (3) the corrugated steel web bears all shear, and the shear stress is evenly distributed along the vertical direction. When using the energy variational method, only the vertical shear strain energy is considered $[20,21]$.

2.2. Kinetic Energy and Potential Energy of the System. Figure 1 is a cross-sectional view of a new type of composite box girder. In the symmetrical bending state, the span of the structure is set as $L$. In order to accurately describe its displacement mode, two displacement functions are introduced, which are vertical dynamic deflection $w(x, t)$ and axial dynamic displacement $Z$, where the expression of displacement function $Z$ is as follows:

$$
\begin{aligned}
Z(x, y, z, t) & =-y\left[\theta(x, t)+\left(1-\bar{z}^{3}\right) u(x, t)\right], \\
\bar{z} & = \begin{cases}\frac{z}{b}, & 0 \leq z \leq b, \\
\frac{(b+\alpha b-z)}{\alpha b}, & b \leq z \leq b+\alpha b,\end{cases}
\end{aligned}
$$

where $\theta(x, t)$ is the section angle of composite box girder and $u(x, t)$ is the function of the maximum longitudinal displacement difference of the wing plate under free vibration.

The calculation formula of the effective shear modulus of corrugated steel web is [22] as follows:

$$
G_{1}=\frac{L_{1}+L_{2} \cos \delta}{L_{1}+L_{2}} \cdot \frac{E_{s}}{2\left(1+v_{s}\right)}
$$

where $E_{S}$ is the elastic modulus of steel and $v_{s}$ is Poisson's ratio of steel. The geometric parameters of corrugated steel web are shown in Figure 2.

During theoretical analysis, the steel bottom plate of composite box girder shown in Figure 1 is converted into equivalent concrete slab by using the conversion section method:

$$
t_{3}=\frac{E_{s}}{E_{c}} t_{s}
$$

where $E_{c}$ is the elastic modulus of concrete; $t_{s}$ is the thickness of steel base plate; and $t_{3}$ is the thickness of converted concrete base plate.

When the new composite box girder vibrates in a steady state, its potential energies are as follows:

(1) The shear strain energy $V_{k}$ of corrugated steel web is

$$
V_{k}=\frac{1}{2} \int_{0}^{l} G_{1} A_{1}\left(w^{\prime}(x, t)-\theta(x, t)\right)^{2} d x .
$$

(2) The dynamic strain energy $V_{y}$ of the upper and lower wing plates of the composite box girder is

$$
\begin{aligned}
V_{y}= & \int_{0}^{l} M(x, t) \theta^{\prime}(x, t) \mathrm{d} x+\frac{E_{c} I_{c}}{2} \int_{0}^{l}\left[\theta^{\prime}(x, t)\right]^{2} \mathrm{~d} x+\frac{I_{c}}{2} \int_{0}^{l} \frac{9 G_{c}}{5 b^{2}}[u(x, t)]^{2} \mathrm{~d} x \\
& +\frac{E_{c} I_{c}}{2} \int_{0}^{l}\left\{\frac{3}{2} \theta^{\prime}(x, t) u^{\prime}(x, t)+\frac{9}{14}\left[u^{\prime}(x, t)\right]^{2}\right\} d x .
\end{aligned}
$$

(3) The total kinetic energy $T$ of the structure is

$$
T=\frac{1}{2} \int_{0}^{l}\left(\rho_{1} A_{1}+\rho_{2} A_{2}+\rho_{3} A_{3}\right) \ddot{w} \mathrm{~d} x+\frac{1}{2} \int_{0}^{l}\left(\rho_{2} I_{2}+\rho_{3} I_{3}\right) \ddot{u} \mathrm{~d} x+\frac{1}{2} \int_{0}^{l}\left(\rho_{2} I_{2}+\rho_{3} I_{3}\right) \ddot{\theta} \mathrm{d} x \text {, }
$$




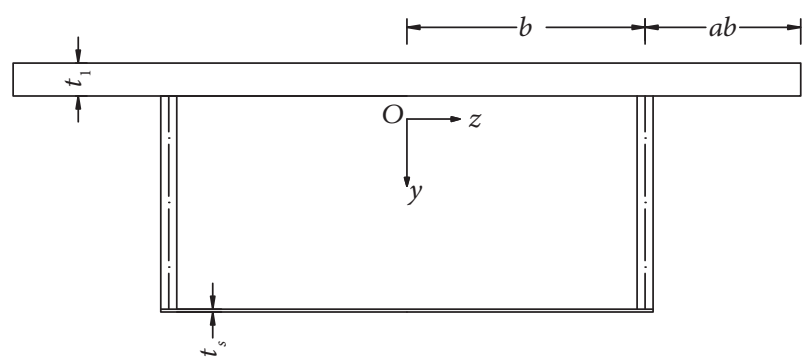

Figure 1: Composite box girder with corrugated steel webs.

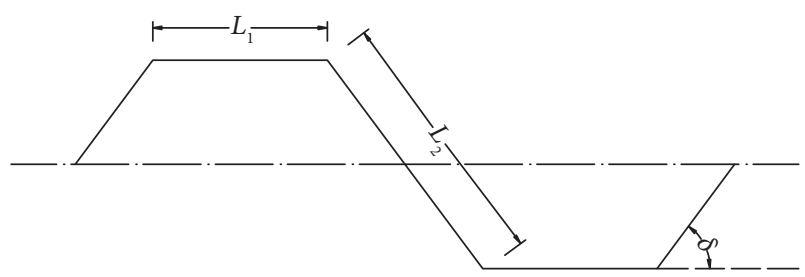

FIGURE 2: Geometric parameters of corrugated steel webs. plate, respectively; $I_{c}$ is the moment of inertia of the upper and lower wing plates of the composite box girder to the neutral axis; $I_{2}$ and $I_{3}$ are the moment of inertia of the upper wing plate and equivalent bottom plate of the composite box girder to the neutral axis, respectively; and $\rho_{1}, \rho_{2}$, and $\rho_{3}$ are the mass density of steel, concrete, and equivalent base plate, respectively.

2.3. Vibration Differential Equation and Natural Boundary Conditions of Composite Box Girder. According to Hamilton' principle, $\delta \int(T-V) \mathrm{d} t=0$ [23].

where $A_{1}, A_{2}$, and $A_{3}$ are the cross-sectional areas of corrugated steel web, upper flange, and equivalent concrete base

$$
\begin{aligned}
-\left(\rho_{1} A_{1}+\rho_{2} A_{2}+\rho_{3} A_{3}\right) \ddot{w}-G_{1} A_{1}\left(\theta^{\prime}-w^{\prime \prime}\right) & =0, \\
-\left(\rho_{2} I_{2}+\rho_{3} I_{3}\right) \ddot{\theta}+Q(x, t)+E_{c} I_{c} \theta^{\prime \prime}+\frac{3 E_{c} I_{c}}{4} u^{\prime \prime}-G_{1} A_{1}\left(\theta-w^{\prime}\right) & =0 \\
-\left(\rho_{2} I_{2}+\rho_{3} I_{3}\right) \ddot{u}+\frac{3 E_{c} I_{c}}{4} \theta^{\prime \prime}+\frac{9 E_{c} I_{c}}{14} u^{\prime \prime}-\frac{9 G_{c} I_{c}}{5 b^{2}} u & =0, \\
{\left.\left[-M(x, t)-E_{c} I_{c} \theta^{\prime}-\frac{3 E_{c} I_{c}}{4} u^{\prime}\right] \delta \theta\right|_{0} ^{l} } & =0, \\
{\left.[\theta-w] \delta w\right|_{0} ^{l} } & =0, \\
{\left.\left[-\frac{3 E_{c} I_{c}}{4} \theta^{\prime}-\frac{9 E_{c} I_{c}}{14} u^{\prime}\right] \delta u\right|_{0} ^{l} } & =0,
\end{aligned}
$$

where $G_{c}$ is the shear elastic modulus of concrete.

$$
\begin{aligned}
& w(x, t)=w(x) \sin (\omega t+\varphi) \\
& u(x, t)=u(x) \sin (\omega t+\varphi) \\
& \theta(x, t)=\theta(x) \sin (\omega t+\varphi)
\end{aligned}
$$
Box Girder

Substituting formulas (13) (15) into formulas (7) (9),

2.4.1. Order.

$$
\begin{aligned}
W^{(6)}+ & {\left[\frac{112 N_{1}}{9 E_{c} I_{c}}+\frac{8 \bar{n} \omega^{2}}{E_{c} I_{c}}+\frac{\bar{m} \omega^{2}}{G_{1} A_{1}}\right] W^{(4)}+\frac{8 \omega^{2}}{E_{c} I_{c}}\left[\frac{\bar{m}\left(\bar{n} \omega^{2}-G_{1} A_{1}\right)}{G_{1} A_{1}}+\frac{14 N_{1}}{9}\left(\frac{\bar{n}}{E_{c} I_{c}}+\frac{\bar{m}}{G_{1} A_{1}}\right)\right] W^{(2)} } \\
& +\frac{112 N_{1} \bar{m} \omega^{2}\left(\bar{n} \omega^{2}-G_{1} A_{1}\right)}{9 E_{c}^{2} I_{c}^{2} G_{1} A_{1}} W=0,
\end{aligned}
$$


where $\bar{m}=\rho_{1} A_{1}+\rho_{2} A_{2}+\rho_{3} A_{3}, \bar{n}=\rho_{2} I_{2}+\rho_{3} I_{3}$, and $N_{1}$ $=\bar{n} \omega^{2}-9 G_{c} I_{c} / 5 b^{2}$.

The analysis of equation (16) shows that the form of the solution of the characteristic equation is as follows:

$$
\begin{aligned}
& r_{1,2}= \pm\left(\alpha_{1}+\beta_{1} i\right)= \pm n_{1}, \\
& r_{3,4}= \pm\left(\alpha_{2}+\beta_{2} i\right)= \pm n_{2}, \\
& r_{5,6}= \pm\left(\alpha_{3}+\beta_{3} i\right)= \pm n_{3},
\end{aligned}
$$

where $\alpha$ is the real part of the solution and $\beta$ is the imaginary part of the solution.

According to the properties of the differential equation, the general solution of equation (16) can be obtained as follows:

$$
w(x)=C_{1} \operatorname{chn}_{1} x+C_{2} \operatorname{shn} n_{1} x+C_{3} \operatorname{chn}_{2} x+C_{4} \operatorname{shn}_{2} x+C_{5} \operatorname{chn} n_{3} x+C_{6} \operatorname{shn}_{3} x .
$$

According to the properties of ordinary differential equations and the principle of identity, the constant coefficients of $\theta(x)$ and $u(x)$ are obtained. Finally, $\theta(x)$ and $u(x)$ are obtained as follows:

$$
\theta(x)=C_{1} B_{1} \operatorname{shn}_{1} x+C_{2} B_{1} \operatorname{chn}_{1} x+C_{3} B_{3} \operatorname{shn}_{2} x+C_{4} B_{3} \operatorname{chn}_{2} x+C_{5} B_{5} \operatorname{shn}_{3} x+C_{6} B_{5} \operatorname{chn}_{3} x
$$

where

$$
\begin{aligned}
B_{1}= & \frac{r+n_{1}{ }^{2}}{n_{1}}, \\
B_{3}= & \frac{r+n_{2}{ }^{2}}{n_{2}}, \\
B_{5}= & \frac{r+n_{3}{ }^{2}}{n_{3}}, \\
r= & \frac{\bar{m} \omega^{2}}{G_{1} A_{1}}, \\
u(x)= & C_{1} \frac{B_{1} n_{1}{ }^{2}}{T_{2}+T_{1} n_{1}{ }^{2}} \operatorname{shn} x+C_{2} \frac{B_{1} n_{1}{ }^{2}}{T_{2}+T_{1} n_{1}{ }^{2}} \operatorname{chn} n_{1} x+C_{3} \frac{B_{3} n_{2}{ }^{2}}{T_{2}+T_{1} n_{2}{ }^{2}} \operatorname{shn} n_{2} x \\
& +C_{4} \frac{B_{3} n_{2}{ }^{2}}{T_{2}+T_{1} n_{2}{ }^{2}} \operatorname{chn} n_{2} x+C_{5} \frac{B_{5} n_{3}{ }^{2}}{T_{2}+T_{1} n_{3}{ }^{2}} \operatorname{shn} n_{3} x+C_{6} \frac{B_{5} n_{3}{ }^{2}}{T_{2}+T_{1} n_{3}{ }^{2}} \operatorname{chn} n_{3} x,
\end{aligned}
$$

where

$$
\begin{aligned}
& T_{1}=-\frac{6}{7} \\
& T_{2}=-\frac{4}{3 E_{c} I_{c}}\left(\bar{n} \omega^{2}-\frac{9 G_{c} I_{c}}{5 b^{2}}\right) .
\end{aligned}
$$

\subsection{Boundary Conditions of Composite Box Girder.}

Geometric and physical boundary conditions of simply supported composite box girder are as follows:

$$
\begin{aligned}
\left.w(x)\right|_{0} ^{l} & =0, \\
\left.w^{\prime \prime}(x)\right|_{0} ^{l} & =0, \\
\left.u^{\prime}(x)\right|_{0} ^{l} & =0 .
\end{aligned}
$$

Equations (19) (22) are substituted or their derivation is brought into the boundary condition of simply supported 
composite box girder, and its natural frequency is calculated by MATLAB software.

\section{Numerical Example}

3.1. Test of Model Beam. The test beam is a new type of simply supported composite box girder with a span of $30 \mathrm{~m}$, and its cross section shape is shown in Figure 1. The concrete material of composite box girder roof is designed according to C50 concrete, and the measured elastic modulus is 34.5 GPa; Q235 steel is used for corrugated steel web and bottom plate, and the elastic modulus is $206 \mathrm{GPa} ; b=1.5 \mathrm{~m}$, $a b=1.5 \mathrm{~m}, t_{1}=0.25 \mathrm{~m}$, and $t_{s}=20 \mathrm{~mm}$. The vertical layout of the test beam and the structure of corrugated steel web are shown in Figure 3.

3.2. Finite Element Model. The finite element analysis software ANSYS is used to establish the finite element model of the new corrugated steel web composite box girder, as shown in Figure 4. The concrete is simulated by SOLID65 element, and the corrugated steel web and steel bottom plate are simulated by shell 63 element.

3.3. Result Analysis. The vertical bending vibration frequency of the new composite box girder is calculated by using the theory in this paper. The results are compared with the finite element and Timoshenko beam theory. The results are shown in Table 1 . The vertical first-order and secondorder vibration modes of composite box girder through finite element analysis are shown in Figure 5.

It can be seen from Table 1 that the bending vibration frequency of the new composite box girder calculated by this method is in good agreement with the finite element results and measured values, which verifies the accuracy of this method. When considering the influence of shear lag effect, the vertical natural frequency of each order of composite box girder decreases accordingly, especially for the high-order frequency, which reaches $7.83 \%$ at the fourth order. Therefore, the shear lag effect cannot be ignored when calculating the high-order frequency of the new composite box girder. If Timoshenko beam theory is used to calculate the vertical fundamental frequency of new wave composite beams, the final result of bridge impact effect will be more safe.

\section{Analysis of Influence of Parameters}

Considering the influence of fold effect on the dynamic characteristics of the new composite box, the corrugated web of the composite box girder as shown in Figure 1 is changed into a flat steel web with equal thickness. In this paper, the fold effect is expressed as follows:

$$
\eta=\frac{f_{p}-f_{x}}{f_{p}} \times 100 \%,
$$

where $f_{p}$ is the frequency value of flat steel web composite box girder and $f_{x}$ is the frequency value of the new composite box girder.
4.1. Influence of Height Span Ratio. In order to study the influence of height span ratio (h/l) on the dynamic characteristics of the new composite box girder bridge, control the structural span and other parameters, and change the height of the composite box girder, the following three calculation models of different box girder heights are established: (1) $\mathrm{h} / \mathrm{l}=0.057$; (2) $\mathrm{h} / \mathrm{l}=0.053$; and (3) $\mathrm{h} / \mathrm{l}=0.050$ (real bridge size). The vertical vibration frequencies of the three models are calculated according to the method in this paper. The results are shown in Table 2.

It can be seen from Table 2 that with the decrease in height span ratio $(h / l)$, that is, the decrease in beam height $(h)$, the first four frequency values $f_{x}$ and $f_{p}$ of the two structures tend to decrease, which shows that increasing beam height $h$ is conducive to improving the vertical stiffness of the structure, and vice versa. With the change of height span ratio, the fold effect value $\eta$ corresponding to each order frequency of the three calculation models changes greatly, indicating that the fold effect is stronger affected by the height span ratio of composite box girder. When the height span ratio is constant, the fold effect value of each vertical order frequency of composite box girder becomes larger, indicating that the influence of fold effect on the vertical bending vibration frequency of composite box girder increases with the increase in order.

4.2. Influence of Width Span Ratio. In order to study the influence of width span ratio $(2 \mathrm{~b} / \mathrm{l})$ on the dynamic characteristics of the new composite box girder bridge, control the structural height and other parameters, and change the composite box girder span $L$, the following three calculation models are established: (1) $2 \mathrm{~b} / \mathrm{l}=0.150$; (2) $2 \mathrm{~b} / \mathrm{l}=0.100$ (real bridge size); and (3) $2 \mathrm{~b} / \mathrm{l}=0.075$. The vertical vibration frequency of the model in 3 is calculated according to the method in this paper. The results are shown in Table 3.

It can be seen from Table 3 that with the decrease in the width span ratio $(2 b / l)$, that is, after the span $(l)$ of the box girder increases, the first four rating values $f_{x}$ and $f_{p}$ of the two structures decrease sharply, which shows that the span $L$ has a great impact on the vertical stiffness of structures such as corrugated steel webs. Comparing the fold effect value $\eta$ of each order frequency of the three calculation models, it can be found that the change is not very large, which shows that the fold effect is less affected by the width span ratio of the composite box girder.

4.3. Influence of Corrugated Web Thickness. In order to study the influence of steel bottom plate thickness on the dynamic characteristics of the new composite box girder bridge, control the structural span and other parameters, and change the corrugated web plate thickness of the composite box girder, the following three calculation models are established: (1) $12 \mathrm{~mm}$ (real bridge size); (2) $16 \mathrm{~mm}$; and (3) $20 \mathrm{~mm}$. The vertical vibration frequency of the model in 3 is calculated according to the method in this paper, and the results are shown in Table 4.

It can be seen from Table 4 that after increasing the thickness of corrugated steel web, the first four frequency 


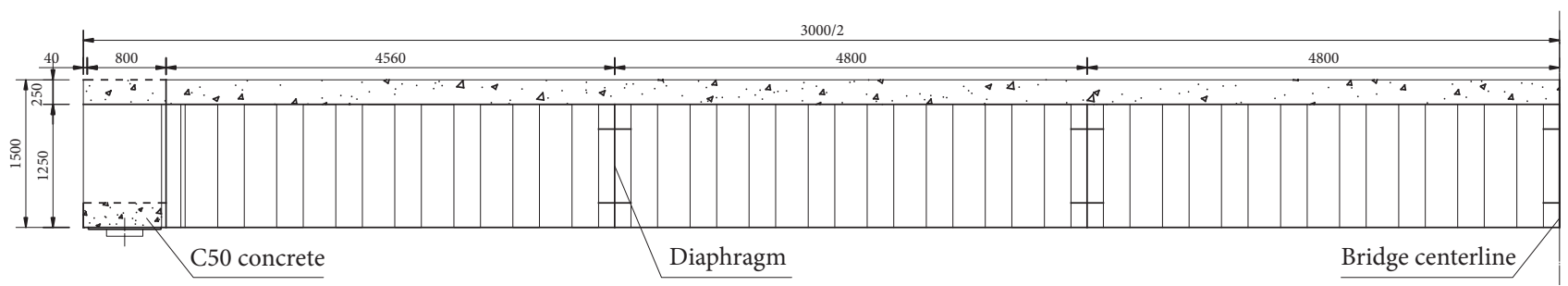

(a)

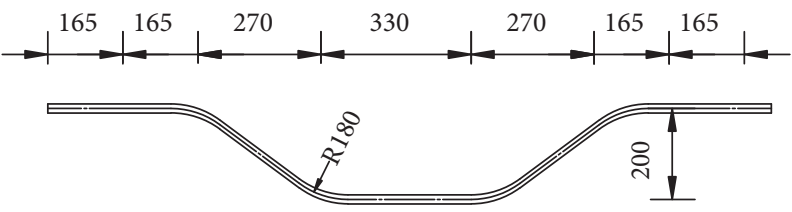

(b)

Figure 3: Test beam façade layout and corrugated steel webs structure $(\mathrm{cm})$ : (a) elevation layout of test beam; (b) construction of corrugated steel web.

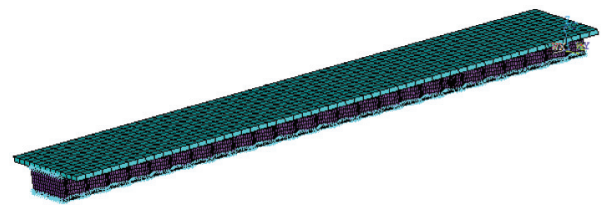

Figure 4: Finite element model for composite box girder.

TABLE 1: Comparison of vibration frequency values of composite box girder $(\mathrm{Hz})$.

Order of frequency Methods in this paper Methods of finite element Timoshenko beam theory Contribution of shear lag (\%)

1 st order

2nd order

3.347

11.672

3.485

3.418

12.297

2.08

3 rd order

22.197

11.840

23.852

4.92

4th order

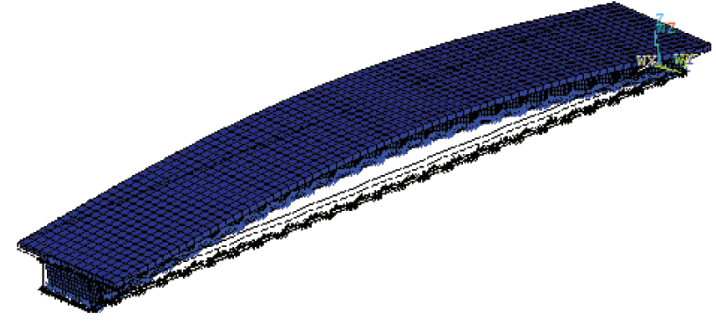

(a)

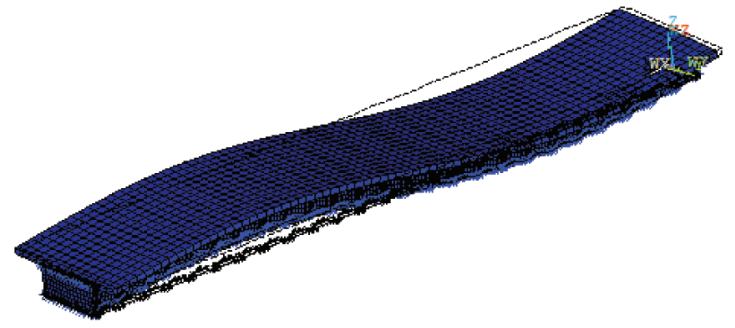

(b)

Figure 5: Structural vibration mode. Finite element analysis of (a) first-order mode and (b) second-order mode.

TABLE 2: Comparison of vibration frequency values of composite box girder with different high span ratios $(\mathrm{Hz})$.

\begin{tabular}{lccccccccc}
\hline \multirow{2}{*}{ Order of frequency } & \multicolumn{3}{c}{$\mathrm{h} / \mathrm{l}=0.057$} & \multicolumn{3}{c}{$\mathrm{h} / \mathrm{l}=0.053$} & \multicolumn{3}{c}{$\mathrm{h} / \mathrm{l}=0.050$} \\
& $f_{x}$ & $f_{p}$ & $\eta(\%)$ & $f_{x}$ & $f_{p}$ & $\eta / \%$ & $f_{x}$ & $f_{p}$ & $\eta(\%)$ \\
\hline 1st order & 3.799 & 4.021 & 5.52 & 3.576 & 3.768 & 5.10 & 3.347 & 3.458 & 3.21 \\
2nd order & 13.073 & 13.931 & 6.16 & 12.396 & 13.129 & 5.58 & 11.672 & 12.131 & 3.78 \\
3rd order & 24.651 & 26.361 & 6.49 & 23.447 & 25.013 & 6.26 & 22.197 & 23.395 & 5.12 \\
4th order & 36.902 & 39.658 & 6.95 & 35.139 & 37.751 & 6.92 & 33.396 & 35.676 & 6.39 \\
\hline
\end{tabular}


TABLE 3: Comparison of vibration frequency values of composite box girder with different width to span ratios (Hz).

\begin{tabular}{lccccccccc}
\hline \multirow{2}{*}{ Order of frequency } & \multicolumn{3}{c}{$2 \mathrm{~b} / \mathrm{l}=0.150$} & \multicolumn{3}{c}{$2 \mathrm{~b} / \mathrm{l}=0.100$} & \multicolumn{3}{c}{$2 \mathrm{~b} / \mathrm{l}=0.075$} \\
& $f_{x}$ & $f_{p}$ & $\eta(\%)$ & $f_{x}$ & $f_{p}$ & $\eta(\%)$ & $f_{x}$ & $f_{p}$ & $\eta(\%)$ \\
\hline 1st order & 7.084 & 7.459 & 5.03 & 3.347 & 3.518 & 4.86 & 1.813 & 1.902 & 4.68 \\
2nd order & 22.201 & 23.623 & 6.02 & 11.672 & 12.349 & 5.48 & 7.078 & 7.450 & 4.99 \\
3rd order & 39.029 & 41.807 & 6.64 & 22.197 & 23.615 & 6.00 & 14.179 & 15.016 & 5.57 \\
4th order & 55.924 & 60.151 & 7.03 & 33.396 & 35.876 & 6.91 & 22.205 & 23.615 & 5.97 \\
\hline
\end{tabular}

TABLe 4: Comparison of vibration frequency values of composite box girder with different corrugated web thicknesses (Hz).

\begin{tabular}{lccccccccc}
\hline \multirow{2}{*}{ Order of frequency } & \multicolumn{3}{c}{$12 \mathrm{~mm}$} & \multicolumn{3}{c}{$16 \mathrm{~mm}$} & \multicolumn{3}{c}{$20 \mathrm{~mm}$} \\
& $f_{x}$ & $f_{p}$ & $\eta(\%)$ & $f_{x}$ & $f_{p}$ & $\eta(\%)$ & $f_{x}$ & $f_{p}$ & $\eta(\%)$ \\
\hline 1st order & 3.347 & 3.458 & 3.21 & 3.361 & 3.567 & 5.78 & 3.368 & 3.612 & 6.76 \\
2nd order & 11.672 & 12.131 & 3.78 & 11.986 & 12.771 & 6.15 & 12.158 & 13.105 & 7.23 \\
3rd order & 22.197 & 23.395 & 5.12 & 23.296 & 24.944 & 6.61 & 24.029 & 25.939 & 7.36 \\
4th order & 33.396 & 35.676 & 6.39 & 35.605 & 38.312 & 7.07 & 37.134 & 40.263 & 7.77 \\
\hline
\end{tabular}

TABLE 5: Comparison of vibration frequency values of composite box girder with different cantilever lengths $(\mathrm{Hz})$.

\begin{tabular}{lcccccc}
\hline Order of & \multicolumn{3}{c}{$\mathrm{ab}=0$} & \multicolumn{3}{c}{$\mathrm{ab}=1.5 \mathrm{~m}$} \\
frequency & $f_{x}$ & $f_{p}$ & $\eta(\%)$ & $f_{x}$ & $f_{p}$ & $\eta(\%)$ \\
\hline 1st order & 4.056 & 4.217 & 0.161 & 3.347 & 3.458 & 0.111 \\
2nd order & 14.335 & 15.008 & 0.673 & 11.672 & 12.131 & 0.459 \\
3rd order & 27.651 & 29.172 & 1.518 & 22.197 & 23.395 & 1.198 \\
4th order & 41.987 & 44.528 & 2.541 & 33.396 & 35.676 & 2.280 \\
\hline
\end{tabular}

values $\mathrm{fx}$ and $\mathrm{fp}$ of the two structures increase, indicating that increasing the thickness of corrugated steel web can improve the vertical stiffness of the structure. With the increase in web thickness, the fold effect value $\eta$ gradually increases, and the first-order and second-order fold effect values of model III $(20 \mathrm{~mm})$ are nearly twice that of model I $(12 \mathrm{~mm})$, indicating that the fold effect has a great impact on the fundamental frequency of composite box girder when the thickness of corrugated web changes, especially when the vertical bending vibration frequency order of composite box girder is low.

4.4. Influence of Cantilever Plate Length. In order to study the influence of the cantilever plate length on the dynamic characteristics of the new composite box girder bridge, control the structural span and other parameters, and change the cantilever plate length of the composite box girder, the following two different calculation models are established: (1) $\mathrm{ab}=0$ and (2) $\mathrm{ab}=1.5 \mathrm{~m}$ (real bridge size). The vertical vibration frequency of model 2 is calculated according to the method in this paper, and the results are shown in Table 5 .

It can be seen from Table 5 that after increasing the length of the cantilever plate, the first four order frequency values $f_{x}$ and $f_{p}$ of the two structures are reduced, and the fourth-order frequencies are reduced by $8.591 \mathrm{~Hz}$ and $8.852 \mathrm{~Hz}$, respectively. The fold effect value $\eta$ of each order frequency of the two calculation models is small, and the maximum fold effect is $2.541 \%$, indicating that the influence of fold effect on cantilever plate length is weak.

\section{Conclusion}

(1) Based on the energy variational principle, after considering the influence of shear lag and shear deformation, the natural frequency equation of simply supported new composite box girder is derived. The obtained frequency analytical solution is in good agreement with the calculated value of ANSYS finite element, which verifies the accuracy of the calculation method in this paper. Therefore, this method has certain theoretical significance and engineering practical value.

(2) Ignoring the influence of shear lag effect, the frequency values of each order of the new composite box girder calculated in this paper are generally large, indicating that the shear lag effect reduces the vertical stiffness of the composite box girder, and the influence of shear lag effect increases with the increase in frequency order;

(3) The folding effect reduces the vertical stiffness of the new composite box girder. The changes of the height span ratio of the composite box girder and the thickness of the corrugated web have a great impact on the folding effect, while the changes of the width span ratio and the length of the cantilever plate have a relatively small impact. It is suggested to reasonably select the corresponding parameters according to the engineering needs to improve the dynamic characteristics of the composite beam bridge.

The mechanical concept of this method is clear and the theoretical basis is reliable, which will provide a good guidance for the design of new corrugated steel web composite box girder. Therefore, it is also hoped that scholars can consider the bending vibration frequency in this paper as the calculation method and improve the calculation accuracy when analyzing the impact coefficient and seismic performance of this kind of bridge in the future. 


\section{Data Availability}

The data generated or used during the study are included within the submitted article.

\section{Conflicts of Interest}

The authors declare that they have no conflicts of interest.

\section{Acknowledgments}

The Young Scholars Science Foundation of Lanzhou Jiaotong University (2018037), Science and Technology Plan of Gansu Province of China (19ZD2GA002), Provincial Natural Science Foundation of Gansu Youth Fund (20JR5RA435), and Gansu University Innovation Fund Project (2020A-026) supported this study.

\section{References}

[1] E. Mohamed, R. W. Hamilton, and A. Seshadri, "Shear strength of beams with corrugated webs," Journal of Structural Engineering, vol. 122, no. 4, pp. 390-398, 1996.

[2] Q. Xu and S. Wan, Design and Application of PC Composite Box Girder Bridge with Corrugated Steel Webs, People's Communications publisher, Beijing, China, 2009.

[3] M. F. Hassanein and O. F. Kharoob, "Shear buckling behavior of tapered bridge girders with steel corrugated webs," Engineering Structures, vol. 74, no. 74, pp. 157-169, 2014.

[4] L. Li, L. Hou, and J. Sun, "Research on shear mechanical property of corrugated steel webs," Journal of Hunan University:Natural Science, vol. 42, no. 11, pp. 56-63, 2015.

[5] S. Zheng and S. Wan, "Torsional vibration characteristic of PC composite box girder with corrugated steel webs," Journal of South China University of Technology:Natural Science Edition, vol. 43, no. 10, pp. 67-73, 2015.

[6] S. D. Song, B. Zhu, K. J. Chen, and B. S. Xiang, "Mechanical performance research on the box girder with corrugated steel webs without considering slippage," Journal of Railway Engineering Society, vol. 189, no. 6, pp. 50-55, 2014.

[7] J. Nie, L. Zhu, and L. Tang, "Shear strength of trapezoidal corrugated steel webs," China Civil Engineering Journal, vol. 46, no. 6, pp. 97-109, 2013.

[8] J. Moon, J. Yi, B. H. Choi, and H.-E. Lee, "Shear strength and design of trapezoidally corrugated steel webs," Journal of Constructional Steel Research, vol. 65, no. 5, pp. 1198-1205, 2009.

[9] E. Mohamed and S. Anand, "Girders with corrugated webs under partial compressive edge loading," Journal of Structural Engineering, vol. 123, no. 6, pp. 783-791, 1997.

[10] S.-A. Ezzeldin Yazeed, "Behaviour of steel and (or) composite girders with corrugated steel webs," Canadian Journal of Civil Engineering, vol. 28, no. 4, pp. 656-672, 2001.

[11] H. Ren, B. Liu, and H. Chen, "Torsional vibration analysis of concrete box girder with corrugated steel webs," Chinese Journal of highway, vol. 21, no. 6, pp. 64-68, 2008.

[12] W. Feng, B. Liu, K. Mou, and H. Wang, "Study on seismic performance of continuous rigid frame bridge with corrugated steel webs," Engineering seismic and reinforcement, vol. 37, no. 05, pp. 70-74, 2015.

[13] R. G. Driver, H. H. Abbas, and R. Sause, "Shear behavior of corrugated web bridge girders," Journal of Structural Engineering, vol. 132, no. 2, pp. 195-203, 2006.
[14] M. E. Eldib, "Shear buckling strength and design of curved corrugated steel webs for bridges," Journal of Constructional Steel Research, vol. 65, no. 12, pp. 2129-2139, 2009.

[15] B. Yang, Study on Construction Control Technology of LongSpan Corrugated Steel Web Continuous Beam bridge, Lanzhou Jiaotong University, Lanzhou, China, 2015.

[16] K. Shen, S. Wan, Z. Jiang, and Y. Mo, "Whole process analysis on pure torsional behavior of concrete composite box girders with corrugated steel webs," Journal of Southeast University (Natural Science Edition), vol. 47, no. 1, pp. 112-117, 2017.

[17] B. Liu, H. Chen, and H. Ren, "Improvement study of the dynamic characteristics for concrete box-girder with corrugated steel webs," China Railway Science, vol. 29, no. 3, pp. 29-33, 2008.

[18] J. Wei and S. Liu, "Influencing factors of vertical frequency of the box beam with corrugated steel webs," Journal of Vibration, Measurement \& Diagnosis, vol. 33, no. 6, pp. 10391043, 2013.

[19] Y. Zhang, P. Huang, D. Jin, and X. Zhou, "Free vibration characteristics and experiment study of composite box girder with corrugated steel webs," Journal of Traffic and Transportation Engineering, vol. 8, no. 5, pp. 76-80, 2008.

[20] C. Ma and S. Liu, "Dynamic behavior analysis of shear lag effect of PC composite box girder with corrugated steel webs," Journal of the China Railway Society, vol. 40, no. 12, pp. 145-152, 2018.

[21] J. Wei, L. Deng, S. Liu, and P. Lin, "Calculation of the vertical bending vibration frequencies of the PC continuous box girder with corrugated steel webs with uniform cross-section," Journal of Vibration and Shock, vol. 35, no. 18, pp. 140-146, 2016.

[22] Y. Gan and G. Zhou, "Analysis of free vibration characteristics of thin-walled box girder based on energy variation principle," China Journal of Highway and Transport, vol. 20, no. 1, pp. 73-78, 2007.

[23] S. Zheng, S. Wan, and H. Cheng, "Research on the dynamic characteristics of multi-room single box composite girder with corrugated steel webs," Journal of Railway Engineering Society, vol. 34, no. 9, pp. 41-46, 2017. 